\title{
Synthesis of Different Ligand Complex Mo (VI) with Stillbazo and Cetylpyridinium Chloride
}

\author{
Shahin M. Bayramov, Aydin M. Pashajanov, Melek M. Agamaliyeva, \\ Gulu G. Abbasova, Zumrud A. Mamedova \\ Institute of Catalysis and Inorganic Chemistry Named after Acad. M. Nagiev, National Academy of Sciences of Azerbaijan, Baku, \\ Azerbaijan \\ Email: iradam@rambler.ru
}

How to cite this paper: Bayramov, S.M., Pashajanov, A.M., Agamaliyeva, M.M., Abbasova, G.G. and Mamedova, Z.A. (2021) Synthesis of Different Ligand Complex Mo (VI) with Stillbazo and Cetylpyridinium Chloride. Journal of Materials Science and Chemical Engineering, 9, 7-12.

https://doi.org/10.4236/msce.2021.912002

Received: October 15, 2021

Accepted: December 21, 2021

Published: December 24, 2021

Copyright $\odot 2021$ by author(s) and Scientific Research Publishing Inc. This work is licensed under the Creative Commons Attribution International License (CC BY 4.0).

http://creativecommons.org/licenses/by/4.0/

\begin{abstract}
The complex of molybdenum (VI) with stilbene-2,2'-disulfonic acid-4,4"bis (azo-1")-3", 4" dioxybenzene (stillbazo) in the presence of a cationic surfactant cetylpyridinium chloride $(\mathrm{CPCl})$ was studied spectrophotometrically. It was found that in the presence of $\mathrm{CPCl}$, a mixed-ligand complex with a component ratio of 1:2:4 is formed. The effect of $\mathrm{pH}$, time, temperature, the concentration of reagents, and $\mathrm{CPCl}$ in the formation of homogeneous ligand and mixed-ligand complexes were studied. The stability constants $\left(\lg \beta_{k}=86 \times 10^{8}\right)$ and the molar absorption coefficient of the mixed-ligand complex $\left(\varepsilon_{\kappa}=11,835\right)$ were determined. It was found that Beer's law is observed at a concentration of $0.05-17.00 \mu \mathrm{g} / \mathrm{ml}$. A method has been developed for the spectrophotometric determination of molybdenum (VI) in complex industrial facilities.
\end{abstract}

\section{Keywords}

Molybdenum, Stillbazo, Surfactant, Spectrophotometric Method

\section{Introduction}

Polyfunctional azopyrocatechols are typical and valuable reagents for the spectrophotometric determination of metal ions [1] [2]. Their analytical capabilities can be significantly expanded if complexation reactions with metal ions are carried out in the presence of a Superficially Active Substance (SAS) [3] [4].

When using SAS, the sensitivity and contrast of the reaction significantly increase, bathochromic and hyperchromic effects are observed, and the $\mathrm{pH}$ of complex formation decreases [3].

In the presence of cationic SAS (cSAS), the group of easily hydrolyzed ele- 
ments W (VI), $\mathrm{Zr}$ (IV), Ti (IV), Mo (VI) is of greatest practical interest [5] [6].

The aim of this work is to study the complexation of Mo (VI) with stillbazo in the presence of a cationic surfactant $(\mathrm{CPCl})$ and use the data obtained for the development of a selective and sensitive spectrophotometric method for the determination of molybdenum (VI).

\section{Experimental Part}

\subsection{Equipment}

The absorption spectra of the complex and reagents were recorded on an SFV-1800 and KFK-2 spectrophotometer. The $\mathrm{pH}$ value of the colored solutions was measured using a BENCHTOP METERS $\mathrm{pH}$ meter.

\subsection{Reagents and Solutions}

A standard solution of molybdenum (VI) with a concentration of $10^{-4} \mathrm{M}$ was prepared from ammonium molybdate. The titer of the solution was determined as described in [7]. Used $5 \times 10^{-3} \mathrm{M}$ aqueous solution of stillbazo, a $10^{-3} \mathrm{M}$ solution of $\mathrm{CPCl}$ was prepared by dissolving a sample of analytical grade reagent in distilled water, followed by heating.

To create a certain acidity of the medium, we used acetate-ammonia solutions, pH 3 - 7, prepared from $2 \mathrm{M} \mathrm{CH}_{3} \mathrm{COOH}$ and $\mathrm{NH}_{4} \mathrm{OH}$. Buffer solutions with $\mathrm{pH} 1$ - 2 were prepared from the standard titrimetric substance of $\mathrm{HCl}$.

\subsection{Methodology}

Mo (VI) solutions of various concentrations $(0.1-17 \mu \mathrm{g} / \mathrm{ml})$ were placed in volumetric flasks with a capacity of $25 \mathrm{ml} .1 .2 \mathrm{ml}\left(2.4 \times 10^{-4} \mathrm{M}\right)$ of stillbazo solution and $1.6 \mathrm{ml}\left(6.4 \times 10^{-5} \mathrm{M}\right)$ of $\mathrm{CPCl}$ solution were added, the volume was brought to the mark with a buffer solution of a standard titrimetric substance $\mathrm{HCl}$ with pH 1 - 2. A blank solution was prepared in a similar way. The optical density of the prepared solutions was measured on a KFK-2 $(1=1 \mathrm{~cm})$ relative to a blank solution.

To construct a calibration graph, $1.6 \times 10^{-4} \mathrm{M}$ stillbazo, $4 \times 10^{-5} \mathrm{M}(\mathrm{CPCl})$, varying concentrations of Mo (VI) were placed in flasks with a capacity of $25 \mathrm{ml}$, and the volume was brought to the mark with a buffer solution of $\mathrm{pH}$ 1.1. The optical density of the prepared solutions was measured by KFK-2 at $640 \mathrm{~nm}$ in a cuvette with $l=1$ relative to the blank experiment.

\section{Results and Its Discussion}

When mixing solutions of molybdenum (VI) and a solution of reagents, a mixedligand complex compound colored in a violet-blue color is formed. The absorption spectra of the reagent with molybdenum, as well as in the presence of $\mathrm{CPCl}$, were recorded in a wide range of wavelengths and at various $\mathrm{pH}$ values of the medium.

It was found that the maximum absorption of the reagent in a weakly acidic 
medium with pH 5.6 is observed at a wavelength of $340 \mathrm{~nm}$, and its single-ligand complex with molybdenum-at $409 \mathrm{~nm}$. Optimum complication conditions are observed at $\mathrm{pH}$ 2.6. For the complete binding of Mo (VI) ions into the complex, $0.6 \mathrm{ml}$ of $1.2 \times 10^{-4} \mathrm{M}$ reagent solution is required.

It was found that in the presence of $\mathrm{CPCl}$, a mixed-ligand complex Mo (VI)tilbazo- $\mathrm{CPCl}$ is formed. The study of the absorption spectra of the mixed-ligand complex depending on the $\mathrm{pH}$ of the medium showed that during its formation the maximum of light absorption shifts to an acidic medium and a longer wavelength region of the spectrum. The maximum yield of the Mo (VI)-tilbazo- $\mathrm{CPCl}$ complex is observed at $\mathrm{pH} 1.1$ and $\lambda=640 \mathrm{~nm}$. For complete binding of $\mathrm{CPCl}$, $0.8 \mathrm{ml}$ of a $3.2 \times 10^{-5} \mathrm{M} \mathrm{CPCl}$ solution is required (Figure 1 ).

The study of the dependence of the formation and stability of the solution of the complexes on time and temperature showed that the homogeneous ligand and mixed-ligand complexes are formed immediately after mixing the solutions of the components and the resulting complexes are stable during the working day and when heated to $70^{\circ} \mathrm{C}$.

In the presence of surfactants, a significant hyperchromic effect and a bathochromic shift are observed in the spectra of the complexes, and the values of optical densities are the maximum, as a rule, at surfactant concentrations close to CMC [8].

A SAS stabilizes a solution of molybdenum-stillbazo, prevents the precipitation of a poorly soluble compound, and acts as a protective colloid, which is usually used in gelatin [9].

It has now been established that the introduction of surfactants in low concentrations in aqueous solutions leads to the effect of water structuring. Hydrocarbon radicals of the introduced substances are located in the voids of water, thereby leading to an increase in the strength of hydrogen bonds in water, i.e., structuring water [10]. It is well known that water molecules are a competing ligand in reactions with organic reagents in aqueous solutions according to the following scheme:

$$
\mathrm{Me}\left(\mathrm{H}_{2} \mathrm{O}\right)_{n}+\mathrm{L} \rightarrow \mathrm{MeL}(\mathrm{OH})_{n-1}+\mathrm{H}_{2} \mathrm{O}
$$

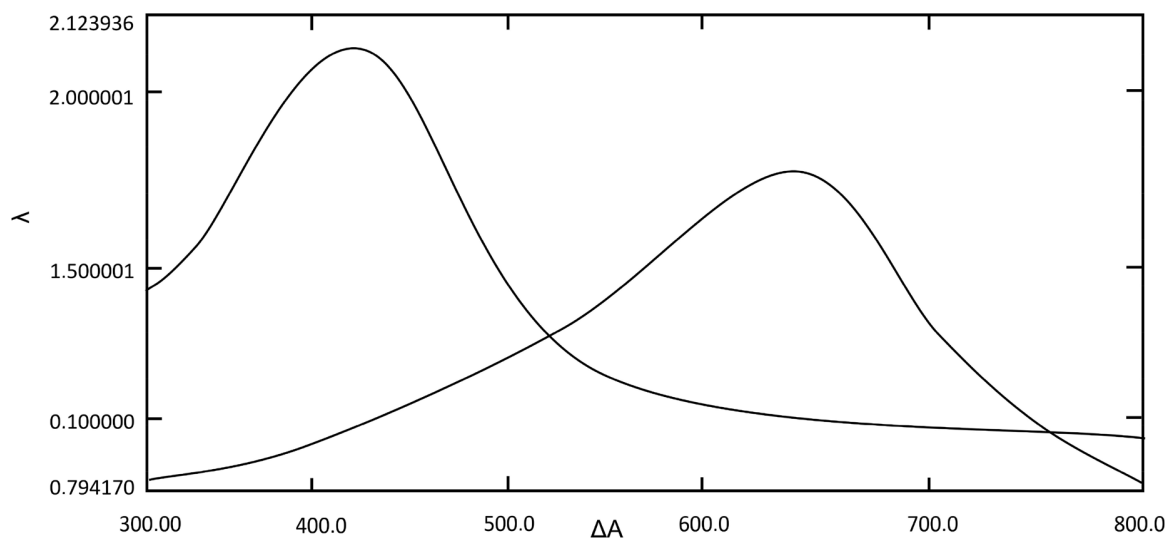

Figure 1. The adsorption spectra of the investigating compounds. 1) Mo (VI)-stillbazo; 2) Mo (VI)-stillbazo-CPCl. $\mathrm{C}_{\mathrm{Mo}(\mathrm{VI})}=1.7 \times 10^{-5} \mathrm{M}, \mathrm{C}_{\mathrm{R}}=2.4 \times 10^{-4} \mathrm{M}, \mathrm{C}_{\mathrm{CP}}=6.4 \times 10^{-5} \mathrm{M}$. 
Therefore, when hydrated molybdenum ions enter the field of structured water near the stillbazo-CP associate, the hydration shell of the molybdenum ion is loosened, as a result of which water is displaced by the ligand and easier coordination of two stillbazo ions becomes possible. A change in the structure of water leads to a change in the constant of water autoprotolysis. As a result, the hydrolysis of molybdenum is suppressed and the concentration of non-hydrolyzed $\mathrm{MoO}_{2}^{2+}$ particles, capable of coordinating two stillbazo ions, increases. This is due to a sharp increase in the concentration of the complex with a large number of attached stillbazo particles in the presence of $\mathrm{CPCl}$.

It was established by the method of isomolar series [11] that the ratio of reagents in the composition of the mixed-ligand and homogeneous-ligand complex $\mathrm{Mo}(\mathrm{VI})$-stillbazo-CPCl = 1:2:4; $\mathrm{Mo}(\mathrm{VI})$-stillbazo $=1: 2$.

According to [11], the 1:2 complex is formed by $\mathrm{MoO}_{2}^{2+}$ ions. Taking into account the state of the reagent and molybdenum (VI), the resulting complexes can be schematically represented in the following form:

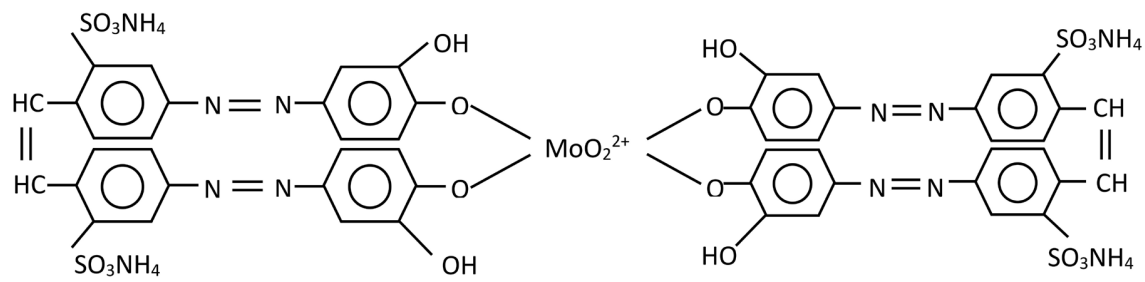

The stability constant of the mixed-ligand complex $\lg \beta_{k}=86 \times 10^{8}$ was determined by the method of curve intersection. With the formation of a mixed-ligand complex, the sensitivity of the reaction increases, i.e., the value of the molar light absorption coefficient increases, respectively, Mo (VI)-stillbazo, Mo (VI)-stillbazo$\mathrm{CPCl} \mathcal{E}_{\kappa}=11835$ and $\mathcal{E}_{\kappa}=68985$ [12].

Beer's law is observed in the range $0.05-17.00 \mu \mathrm{g} \mathrm{Mo}(25 \mathrm{ml})$.

The influence of foreign ions and masking substances on the photometric determination of Mo (VI) has been studied. It was found that with the formation of a mixed-ligand complex, the selectivity and contrast of the reaction increase. The complexation is interfered with the ions $\mathrm{W}$ (VI), Fe (III), Ti (IV).

The developed technique was applied to determine Mo (VI) in industrial complex objects.

\section{Determination of Molybdenum in Steels}

$1 \mathrm{~g}$ of a sample of steel is dissolved in $50 \mathrm{ml}$ of $\mathrm{HCl}$ (1:1), adding a few milliliters of $\mathrm{HNO}_{3}$ (1:1) during dissolution. The solution is evaporated to $2-3 \mathrm{ml}$, transferred to a $100 \mathrm{ml}$ volumetric flask, and the volume is adjusted to the mark with distilled water. An aliquot part (1 - $3 \mathrm{ml})$ is placed in a $25 \mathrm{ml}$ volumetric flask, to which a buffer solution of $\mathrm{pH} 1.1$ was previously added, then $5 \mathrm{ml}$ of a $5 \%$ solution of ascorbic acid, $0.8 \mathrm{ml}$ of $5 \times 10^{-3} \mathrm{M}$ stillbazo solution, $1 \mathrm{ml} 1 \times 10^{-3} \mathrm{M}$ solution of $\mathrm{CP}$, bring the volume to the mark with buffer solution $(\mathrm{pH} 1.1)$ and after $5 \mathrm{~min}$. measure the optical density at $640 \mathrm{~nm}(1=1 \mathrm{~cm})$ (Table 1$)$. 
Table 1. Results of the determination of molybdenum in steels $(n=3, p=0.95)$.

\begin{tabular}{cccc}
\hline Object & Mo content according to the passport, \% & Found Mo, \% & Sr \\
\hline Steel 86 e & 0.21 & $0.22 \pm 0.05$ & 0.049 \\
Steel 316 & 2.77 & $2.75 \pm 0.02$ & 0.013 \\
\hline
\end{tabular}

\section{Conclusion}

The complexation of molybdenum (VI) with stillbazo was studied in the presence of a cationic surfactant $(\mathrm{CPCl})$. It was found that in the presence of surfactants, the light absorption of the mixed-ligand molybdenum complex significantly increases, the bathochromic effect is observed in the absorption band spectrum, and complexation shifts to a more acidic region. The composition of Mo (VI)-stillbazo- $\mathrm{CPCl}=1: 2: 4$ complex was determined by various spectrophotometric methods. The stability constant $\left(\lg \beta_{k}=86 \times 10^{8}\right)$ and the molar absorption coefficient $\left(\varepsilon_{K}=11835\right)$ of the complex were determined. It was found that Beer's law is observed at a Mo (VI) concentration of $0.05-17 \mu \mathrm{g} / \mathrm{ml}$. A method for the photometric determination of molybdenum in industrial facilities has been developed.

\section{Conflicts of Interest}

The authors declare no conflicts of interest regarding the publication of this paper.

\section{References}

[1] Myasoedova, A.S., Ivanov, V.M., Busev, A.I. (1977) Stability Constants of Tungsten(6) Complexes with Azo Derivatives of Pyrocatechol. Zhurnal Analiticheskoj Khimii, 32, 490-496.

[2] Bayramov, S.M., Pashajanov, A.M., Abbasova, G.G., Gambarova, M.I. and Gasanova, S.M. (2019) The Coordination Compound of Ga(III) with Stillbazo in the Presence of Cetyl Pyridinium Chloride as a Surface Active Compound. Journal of Materials Science and Chemical Engineering, 7, 58-63. https://doi.org/10.4236/msce.2019.710006

[3] Poledmok, J., Orzel, J., Galeczka, J. and Çzoik, P. (2017) A Highly Sensitive Spectrophotometric Method for Gallium Determination with Chrome Azurol S in the Presence of Mixed Cationic-Nonionic Surfactants and Its Application in Plant Analysis. Communications in Soil Science and Plant Analysis, 48, 936-942. https://doi.org/10.1080/00103624.2017.1311907

[4] Lomako, E.V. and Kuzmicheva, N.A. (2014) The Use of Surfactants in the Analysis of Medicinal Plant Materials Containing Flavonoids. Pharmacy Bulletin, 65.

[5] Ibragimova, S.A., Zalov, A.Z., Verdizade, N.A. and Hajiyeva, A.B. (2017) Analytical Application of Ion Associates of Molybdenum and Tungsten with 2-Hydroxy-5-Bromothiophenol and Hydrophobic Amines. Azerbaijan Chemical Journal, 39.

[6] Lalithav, S., Raghavendra, Guru, P.A. and Raman, K.K. (2010) Spectrophotometric Determination of Trace Amounts of Molybdenum (VI) Using Salicylaldehyde Acetoacetic Acid Hydrazone. Chemical Bulletin of Politehnica University of Timisoara, 55, 110. 
[7] Korostelev, P.P. (1964) The Preparing of Solutions for Chemico-Analytical Works. Science, 261.

[8] Strelkova, K.V., Varigina, O.V., Chernova, R.K., Koblova, O.E. and Kostrutsky, A.Y. (2017) O vzaimodeystvii synteticheskogo pishevogo krasitelya E133 s kationami cetylpridiniu. Izvestiya Saratovskoqo Universiteta, 17, 376-381. (in Russian) https://doi.org/10.18500/1816-9775-2017-17-4-376-381

[9] Savvin, S.B., Chernova, R.K. and Lobacheva, I.V. (1981) Effect of Deprotonation of Triphenylmethane Group Reagents in the Presence of Cationic Surfactants and Its Influence on Complexing of Disulfophenylfluorone and Bromopyrogallol Red with Metal Ions. Journal of Analytical Chemistry, 36, 9.

[10] Chernova, R.K. (1977) Influence of Some Colloidal Surfactants on the Spectrophotometric Characteristics of Metal Chelates with Organic Chromophore Reagents. Journal of Analytical Chemistry, 32, 1477.

[11] Chernova, R.K. and Lobacheva, I.V. (1978) Structure and Properties of Molecules. Interuniversity Scientific Collection, Issue 3, Publishing House of Kuibyshev University, Kuibyshev, 109.

[12] Bulatov, M.I. and Kalinkin, N.P. (1986) Practical Guide to Photometric Method. Chemistry, 432. 